\title{
Renewable energy based microgrid system sizing and energy management for green buildings
}

\author{
Y. V. PAVAN KUMAR ( $₫)$, Ravikumar BHIMASINGU
}

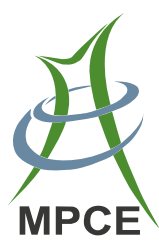

\begin{abstract}
The objective of this paper is to model a hybrid power system for buildings, which is technically feasible and economically optimal. With a view to promote renewable energy sources, photovoltaics and wind turbines are integrated with the grid connected building. The system is modeled and the optimal system configuration is estimated with the help of hybrid optimization model for electric renewables (HOMER). The logic is illustrated with a case study based on the practical data of a building located in southern India. This building is associated with 3.4 MWh/day priority load (peak load as $422 \mathrm{~kW}$ ), as well as $3.3 \mathrm{MWh} /$ day deferrable load (peak load as $500 \mathrm{~kW}$ ). Sensitivity analysis is performed to deal with uncertainties such as the increase in electricity consumption and grid tariff, environmental changes, etc. From the simulation result, it is observed that the designed system is cost effective and environment friendly, which leads to $6.18 \%$ annual cost savings and reduces $\mathrm{CO}_{2}$ emissions by $38.3 \%$. Sensitivity results indicate that the system is optimal and adaptable in a certain range of unanticipated variances with respect to best estimated value. Finally, an energy management strategy is developed for the optimal system to ensure reliable power during contingency and disturbances. The green and hybrid power system designed can be adaptable to any critical and large consumers of urban buildings.
\end{abstract}

CrossCheck date: 4 January 2015

Received: 14 October 2014 / Accepted: 7 January 2015/Published online: 23 January 2015

(C) The Author(s) 2015. This article is published with open access at Springerlink.com

Y. V. PAVAN KUMAR, R. BHIMASINGU, Department of Electrical Engineering, Indian Institute of Technology

Hyderabad (IITH), Hyderabad, India

$(\bowtie)$ e-mail: ee14resch01008@iith.ac.in

R. BHIMASINGU

e-mail: ravikumar@iith.ac.in
Keywords Renewable energy sources (RES), Hybrid power systems (HPS), Photovoltaic (PV), Wind turbine (WT), Low-carbon electricity, Energy management, Total net present cost (TNPC)

\section{Introduction}

India, a dwelling place for 1.21 billion people, which is over $17 \%$ of the world's population, has a seemingly unquenchable thirst for energy. One blaring result of its meteoric growth is the widening gap between the energy demand and the supply; therefore, the government is paying increased focus to bridge the gap by capacity addition. In chorus, attention is being paid to that the growth should be in a sustainable manner while addressing the climatic change concerns. In 2008, with the announcement of the National Action Plan on Climate Change (NAPCC), there is a marked shift in policy to diversify the energy mix to the lower carbon intensity [1]. Besides, low-carbon generation systems bring competition in electricity markets and are in turn improves the country's sustenance and economy [2]. Nowadays, the country is promoting renewable energy to augment the total power supply and to meet the rural needs either by augmenting grid supply or by offgrid supply.

The statistics show that approximately $38 \%$ of the total electric energy production is being consumed by the industrial sector, which is playing a crucial role in the economic growth of the country. With India emerging as an IT/BPO hub, erratic power supply hampers the business process, which ultimately reflects on the country's economy. Besides, cross subsidies, higher tariff, power outages, load shedding and inconsistent quality of power supplied by utilities are other factors that adversely affect such industries. With the demand far outstripping the electricity 
generation in the country, many industries are now looking at alternatives based on the guidelines and roadmaps given by various forums and government bodies for clean energy generation [3, 4]. The solution as envisioned by many organizations is to set up captive power plants for electricity generation or diesel generator set as a back-up, which is again not a clean energy.

In this framework, the hybrid and green power system uses renewable energy resources that are available at the site of use and are used to produce electricity in and around the premises of the building in an economic way. An energy management strategy is developed, which ensures uninterruptable power supply to all the priority loads connected to the building. Optimization result shows that the system is cost effective and reliable with less carbon emission. Sensitivity analysis shows that the system performance is nearly optimal in all scenarios.

\subsection{Literature review}

Below literature indicates some of the related works carried out in the design of low-carbon electricity systems. Various studies were done on microgrid formation for a particular combination of distributed units in a location. This paper deals with the formation of microgrid with various combinations of distributed resources to achieve a sustainable design for the low-carbon power system. Further, it compares all the combinations in terms of cost and carbon emissions to select best sized microgrid for a specific case study. Finally, optimum energy usage is achieved by the design of energy management strategy.

Reference [5] identified and suggested some insights for the people live in Germany and USA to choose and develop low-carbon electrical power generation systems. It also presented the advantages of low-carbon initiatives and crisis with the nuclear based generation systems briefly. Reference [6] presented the design of low-carbon optimum evaluation model by using multi-objective function to improve the efficiency of carbon footprint calculations. This considers dealer manufacturing capacity, green-house gas values, product components transport modes, design phase costs, as well as the product decisions made by enterprises. Reference [7] presented the scenarios and consideration of combined nuclear and renewable based energy systems design in Japan in 2030 to adhere the country's policies of $\mathrm{CO}_{2}$ emission reduction. The safe and clean electricity was analyzed for "smart control" on both demand and supply sides. Reference [8] presented wholesystems method to appreciate the role of grid-scale electricity storage by concurrently optimizing investment into network and storage capacity, new generation. This minimizes system operation cost by considering system's reserve and security constraints. Reference [9] presented an integrated methodology that considered demand responses and renewable generation as inputs for the distribution system planning to make the system as a low-carbon sustainable system. This method optimized the allocation of renewable/non-renewable units and smart metering units simultaneously to minimize total carbon emissions cost. Similar integrated model for low-carbon power generation in China was presented in [10]. Reference [11] presented a comprehensive model to study low-carbon power system dispatches. The operating mechanisms and characteristics were analyzed by considering feasible power output limits, rates, and the carbon emissions. Reference [12] presented a generation output model to evaluate the power dispatch problems under low-carbon and economy systems development. In [13-16], similar analysis was carried out for the design of low-carbon electricity systems and study on their impacts on the energy crunches for different cases.

Reference [17] presented the design of hierarchical control for microgrids. Energy management system was designed to achieve a reasonable balance between generation and battery usage. However, the system was developed only for island mode but not for grid tied mode. Reference [18] presented the dynamic behavior of a mixed system consisting of a wind farm and a diesel group supplying a load, under different disturbances. Reference [19] presented two droop control strategy for distributed generation in interconnected grids. Reference [20] presented a simulation model to investigate specific hybrid architecture, which is based on the use of DC bus, DC/AC and DC/ $\mathrm{DC}$ converters for power sources. This increases number of converters usage and leads to high cost and poor quality. Reference [21] had done an optimal cost analysis of hybrid renewable system using hybrid optimization model for electric renewables (HOMER). The real time cost analysis and system optimization was done based on the load profile, solar radiation and wind speed. Reference [22] and [23] described the integration of wind power into traditional diesel-only power system, which reduced greenhouse gases and thereby global warming. The wind-diesel power plant was designed, and the operational and economic analysis were compared with traditional diesel system using HOMER. In [24], the distributed energy resource system was designed and simulated. The cost analysis was done by calculating net present value. Reference [25] presented microgrid with micro-controller based energy management unit. Hydro generators, PV panels, and diesel generators were integrated to study the generation patterns under various ecological conditions. Reference [26] presented a voltage and frequency control strategy for active island microgrids design. There are few literatures available on the study of economic and technical feasibility of microgrids and hybrid systems in [27-33]. However, most of these were designed for standalone systems of remote 
areas, where it is either difficult or impossible to extend the grid service. And these studies considered the loads in a nonspecific manner. This paper focuses on the grid-connected HPS developed for a practical case study.

\section{Hybrid power based microgrid description}

Microgrids are formed by the hybrid interconnection of various units such as $\mathrm{AC}$ and $\mathrm{DC}$ energy sources, storage, $\mathrm{AC}$ and DC loads, AC/DC, DC/DC, or DC/AC converters. The selection of any architecture for a location depends on the geographical, economical, and technical factors at that location. The architectural segregations are as follows.

1) In the view of operation: stand-alone/off-grid/islanding mode and grid connected mode architectures.

2) In the view of integration: centralized DC bus (Fig. 1), centralized AC bus (Fig. 2), distributed AC bus (Fig. 3), hybrid coupled (AC-DC) bus (Fig. 4) architectures.

\section{Case study description}

In this case study, the considered building is an organization located at Hyderabad, India. The area enclosed by the building is about $125000 \mathrm{sq} \mathrm{ft}$. The existing architecture of the building is that it is connected to the utility grid

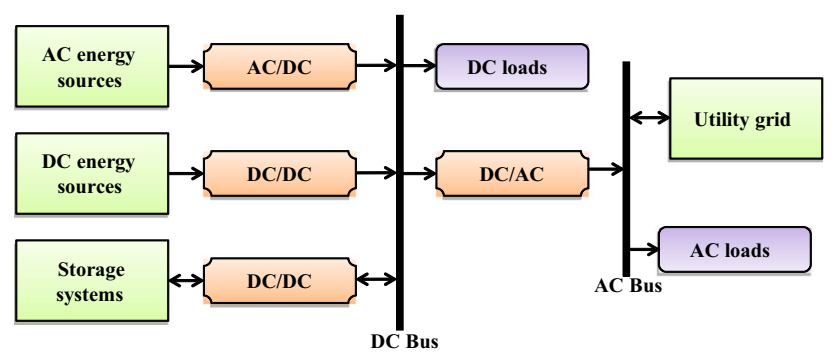

Fig. 1 Centralized DC bus architecture of microgrid

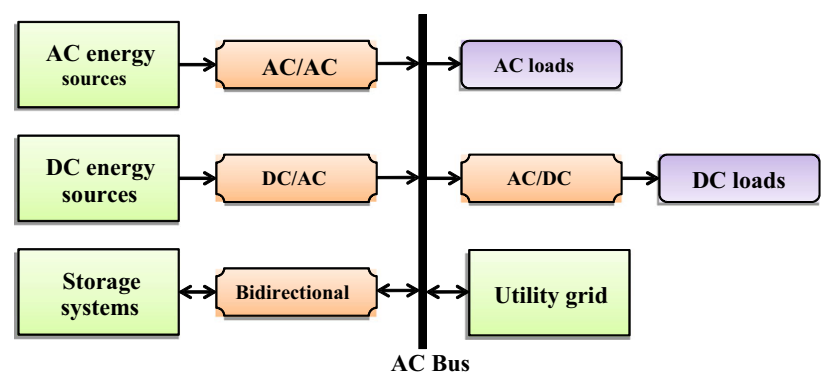

Fig. 2 Centralized AC bus architecture of microgrid

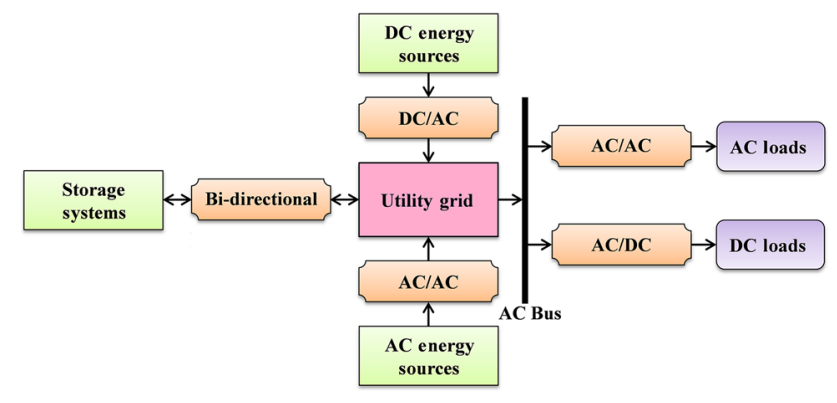

Fig. 3 Distributed AC bus architecture of microgrid

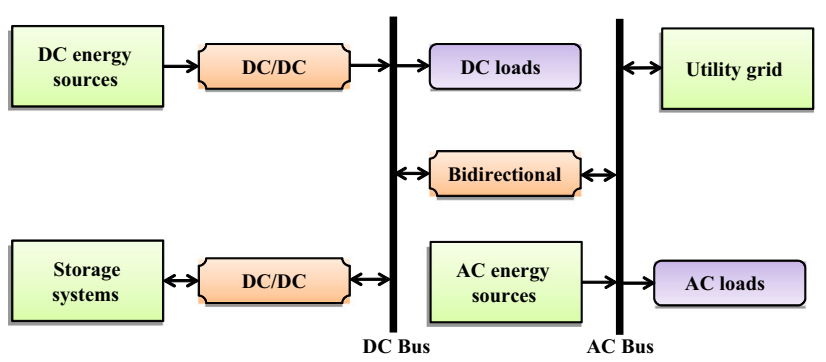

Fig. 4 Hybrid coupled (AC-DC) bus architecture of microgrid

that serves the entire load connected. A diesel generator set was also installed to meet certain portion of the load at the time of grid outage. The new proposed architecture of the system is that the electric energy produced from the PV and WT augments the grid supply to meet the demand. A converter is connected to convert the DC power produced by the PV array to AC, as the entire load served is the AC type. A $396 \mathrm{~V}$ battery bank is also connected to the DC bus, which can store energy and be used as a backup energy source. The system is modeled, and the best configuration of hybrid system is estimated by using HOMER [34, 35]. The profiles of load demands and energy resources are given as follows.

\subsection{Load profile}

The analysis does not perceive the entire load connected to the building. Moreover, it categorizes the load in the most smart and reasonable way. The type of load that is connected to this building and other such buildings are heating, ventilation, and air conditioning (HVAC) load, uninterrupted power supply (UPS) load, air handling unit (AHU) load, lighting load and other utility loads. These loads are further classified as shown in Table 1.

\subsubsection{Priority load}

These loads are electrical demand that the power system must serve at a specific time. In any business or industry, 
Table 1 Categorized breakdown of building loads

\begin{tabular}{llc}
\hline Load category & Particulars & $\begin{array}{l}\text { Total energy } \\
\text { consumption/\% }\end{array}$ \\
\hline Priority load & UPS & 32 \\
& Lighting & 10 \\
& Elevators & 7 \\
Deferrable load & Others & 2 \\
& HVAC & 31 \\
& Pump Load & 8 \\
& AHU & 6 \\
& Others & 4 \\
\hline
\end{tabular}

computers are the integral part, thus all the UPS load is considered as a priority load. Other loads associated with this category are lighting load and some utility loads like elevators. As these loads varies according to time of the day and also do not attain the same value for weekdays and weekends, a separate survey for this category of loads is needed. The variation of this load is recorded for a year (separately for weekday and weekend), to make the data more realistic. An average $5 \%$ day-to-day and hour-to hour randomness are added to the practical data such that load profile of each day is unique. Figs. 5 and 6 illustrates a typical profile of the priority load.

\subsubsection{Deferrable load}

Deferrable loads can be classified as an electrical demand that can be met anytime within a definite time interval. Typical example of this load type is the chiller

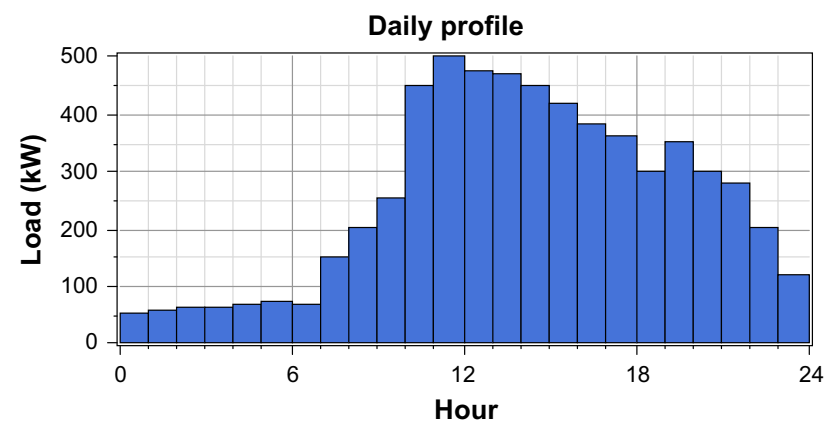

Fig. 5 Hourly profile of priority load in a weekday

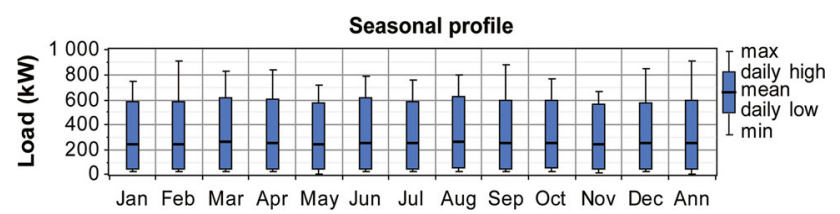

Fig. 6 Monthly profile of priority load in a year load, AHU load, water pump load, battery charging station, etc. Certain amount of energy is stored in such type of devices and is generally switched on intermediately. For example, after the chiller unit and the pump associated with it are charged to its full capacity, it can serve the building for certain period without demanding electrical input. This type of load is often advantageous as one can track the level of energy that is stored in this load type, and can put excess renewable energy into this as long as energy level is above zero. Once the energy level drops to zero, these loads can be treated as a priority load and can be served immediately. The typical monthly variation of such load type is shown in Fig. 7.

\subsection{Solar and wind resources}

The considered building is located at a latitude of 17.37 (North), longitude of 78.47 (East), and an altitude of $536 \mathrm{~m}$. It experiences a combination of tropical wet and dry climate [36]. The place is blessed with around $5.34 \mathrm{kWh} / \mathrm{m}^{2}$ yearly average daily solar radiation and more than $6 \mathrm{kWh} / \mathrm{m}^{2}$ maximum radiation in March, April and May. The radiation data can be obtained from the database of NASA [37]. The monthly average of solar radiation and clearness index is shown in Fig. 8. Recorded data shows that the monthly wind speed in a year is $4.141 \mathrm{~m} / \mathrm{s}$. Fig. 9 illustrates the wind speed variation throughout the year [38]. From the solar and wind resource data, it is clear that

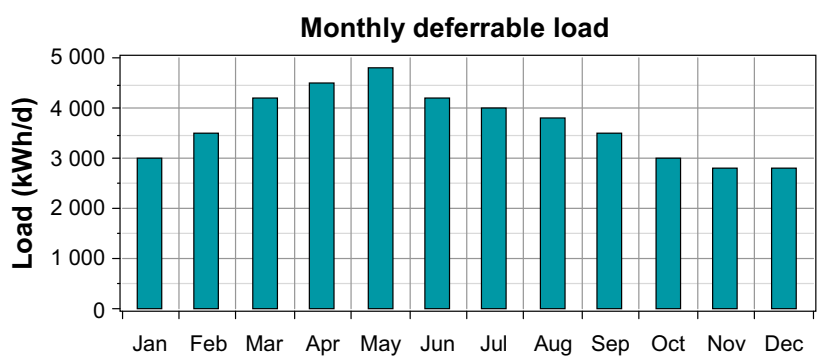

Fig. 7 Monthly profile of deferrable load in a year

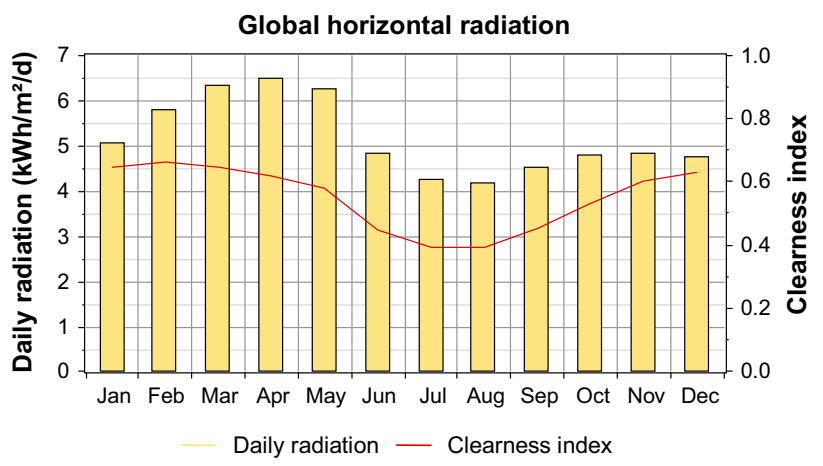

Fig. 8 Profile of solar radiation and clearness index in a year 


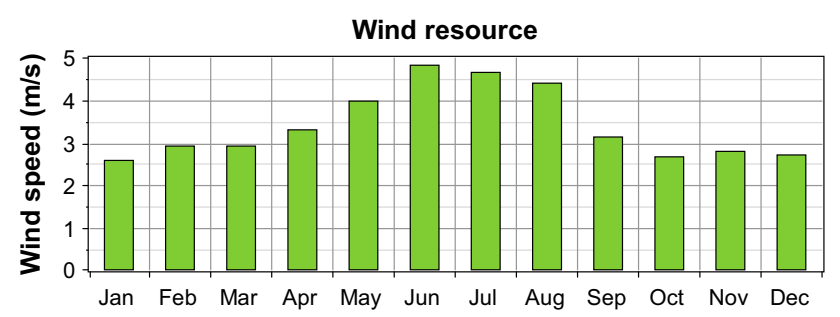

Fig. 9 Monthly profile of wind resource in a year

June, July, and August are experiencing less solar radiation, but the wind speed compensates this effect and makes the total natural resource available throughout the year.

\section{Hybrid power system modeling and simulation}

\subsection{Introduction to HOMER and system simulation}

HOMER is a micro-power optimization tool, which is developed by the U.S. National Renewable Energy Laboratory (NREL). It models the physical behavior of a power system and calculates its lifecycle cost or the total net present cost (TNPC), which includes installation and operating cost of the system over its life span. The modeler provides the solar and wind resources data, load profile of the building to be served by the HPS, components to be considered and their cost as input to the HOMER. The HOMER then performs an hourly energy balance calculation for each configuration for a year. After simulating all the possible configurations, the infeasible configurations are discarded and the feasible solutions are ranked according to the TNPC. It also allows the user to perform the sensitivity analysis on various inputs to access the effects of uncertainty on which the system has no control. Fig. 10 illustrates the relationship among simulation, optimization and sensitivity analysis. The optimization oval encloses the simulation oval to represent the fact that a single optimization consists of multiple simulations. Similarly, the sensitivity analysis oval encompasses optimization oval, representing that a single sensitivity analysis consists of multiple optimizations.

\subsubsection{Simulation}

Microgrid architectures with different combinations of distributed resources are developed for the performance analysis in each hour of the year to determine its technical feasibility and life-cycle cost. Energy balance calculations are performed based on the system architecture consisting of different combinations of the components. This paper chooses PV, WT, diesel generators, battery, and converter

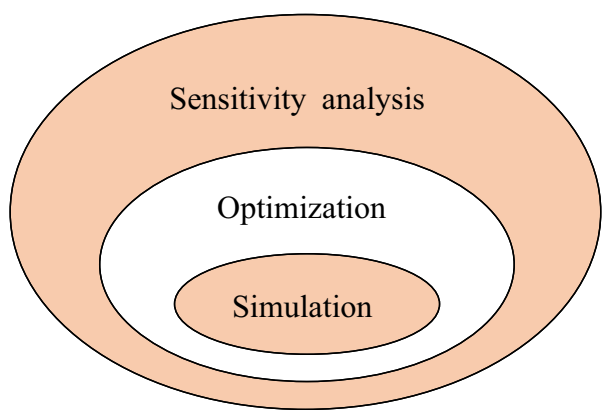

Fig. 10 Relationship among simulation, optimization, sensitivity

as the elements of HPS and the best feasible configuration is determined that can adequately serve the load.

\subsubsection{Optimization process}

Power system should be appropriately designed in terms of economy, reliability, and ecological measures subjected to various physical and operational constraints of the location. The optimal system configuration can be decided with the mixture of components that the system should comprise the quantity of each component and the dispatch strategy the system should use. The overall objective is to identify a configuration which has low TNPC. Therefore, different system configurations and technical constraints are simulated and formed various combinations of system components. Finally, a list of configurations are sorted out and compared. Best feasible combinations are extracted and the least feasible ones are omitted. The overall optimization process is shown in Fig. 11. The objective function of the optimization problem is given by (1).

$\min (T N P C)=\min \left(\sum T N P C\left(C_{i}\right)\right)$

where TNPC can be calculated by (2).

$T N P C\left(C_{i}\right)=N_{i} \times\left(C p t l C_{i}+\left(R p l C_{i} \times M_{i}\right)+\frac{O M C_{i}}{C R F}\right)$

Overall system annualized cost $\left(C_{i}\right)$ in general form is calculated as the sum of costs of all components and is given by (3). This cost consists annualized costs of the components procurement, replacement, and operations including fuel maintenance. Hence, the total TNPC value is calculated as the sum of TNPC of each component.

$C_{i}=C_{P V}+C_{W T}+C_{D G}+C_{C O N V}+C_{B A T}$

$C R F=\frac{i r(1+i r)^{R}}{(1+i r)^{R}-1}$

where $C_{P V}, C_{W T}, C_{D G}, C_{B A T}, C_{C O N V}$ are the costs of PV, WT, diesel generator, battery, and converter; $i$ the index 


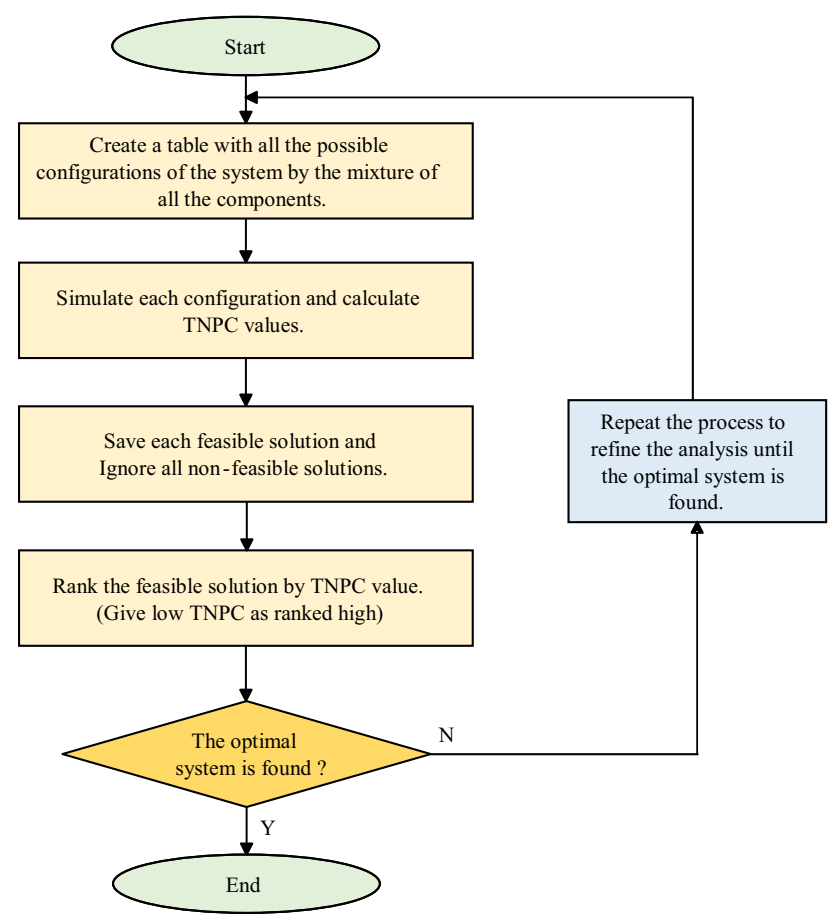

Fig. 11 Flow chart for the optimization process

of PV, WT, battery, converter, and diesel generator; $N_{i}$ the total number of system components; $\mathrm{Cptl}_{i}$ the capital cost of a component; $\mathrm{RplC}_{i}$ the replacement cost of a component; $M_{i}$ the single payment present worth of a component; $O M C_{i}$ the operation and maintenance cost of a component; $C R F$ the capital recovery factor; $R$ the project lifetime; and ir the annual interest rate for the project life time.

\subsubsection{Sensitivity analysis}

As the TNPC varies based on sensitivity variables chosen, in this analysis, multiple optimizations are performed to measure the effects of the uncertainties such as wind speed, solar radiations, grid tariffs, and fuel prices on the system performance. Hence, the HPS configuration has to be chosen to tolerate all these situations.

\subsection{Microgrid system modeling}

The microgrid system is formed as an interconnection of various distributed units such as PV, WT, utility grid, diesel generator, converter, and battery that are modeled as shown below. It is important to know the technical and economic detail of these units precisely to get an accurate simulation result. Besides, decisions on system control parameters, constraints, and economic inputs have an equal effect on the simulation results.

\subsubsection{PV panel modeling}

The model of the PV array is developed that it produces DC electricity in direct proportion to the global solar radiation. It is independent of temperature and voltage to which it is exposed. Output power is given by (5).

$P_{P V}=f_{P V} Y_{P V} \frac{I_{T}}{I_{S}}$

where $f_{P V}$ is $\mathrm{PV}$ derating factor; $Y_{P V}$ the rated capacity of the PV array; $I_{T}$ the global solar radiation incident on the surface of the PV array; and $I_{S}$ is $1 \mathrm{~kW} / \mathrm{m}^{2}$ which is the standard amount of radiation used to rate the $\mathrm{PV}$ capacity.

The range of the PV array rating is permitted to vary between $125 \mathrm{~kW}$ and $275 \mathrm{~kW}$ to choose the optimal size. The capital cost of the PV panel is $3500 \$ / \mathrm{kW}$ and after a reasonable percentage of discount on bulk amount, the replacement cost is considered as $3400 \$ / \mathrm{kW}$. The subsidy provided for using solar energy was also discounted in the given capital cost. Operation and maintenance cost for the $\mathrm{PV}$ array is considered as $0 \$$. The lifetime of the selected PV array is 25 years with a derating factor of $85 \%$. Twoaxis tracking system is established for the PV panel.

\subsubsection{WT power unit modeling}

Wind turbine converts kinetic energy of the wind into AC electricity according to a particular power curve. Each hour, power output of the wind turbine is calculated in a four-step process. Firstly, it determines the average wind speed for the hour at the anemometer height by referring to the wind resource data. Secondly, it calculates the corresponding wind speed at the turbine's hub height using either the logarithmic law or the power law. Thirdly, it refers to the turbine's power curve to calculate its power output at that wind speed assuming standard air density. Fourthly, it multiplies output power by air density ratio.

The rating of each wind turbine considered is $50 \mathrm{~kW}$, AC. Range of 2 to 5 numbers of such turbines is taken as decision variable. The cost of each wind turbine is $181035 \$$. The subsidy provided to set up wind firm is deducted in the given capital cost. Operation and mainte-

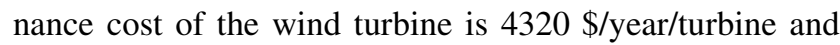
the total operation and maintenance cost is reduced as the number of turbines increases. The lifetime of the turbine is 25 years and the height of the turbine hub is $40 \mathrm{~m}$.

\subsubsection{Battery system modeling}

Batteries are used to store excess power in the HPS, and to operate when the system has deficit power. Its life 
depends on how many times the battery is charge/ discharge per day. Battery bank is formed for $396 \mathrm{~V} \mathrm{DC}$ bus. The rating of each battery is $12 \mathrm{~V}, 200 \mathrm{Ah}, 2.4 \mathrm{kWh}$. A string of 33 such batteries are connected in series to deliver the power at a desired voltage level. The cost of each battery is $475 \$$ and the replacement cost is $430 \$$. The battery lifetime is 10 years. Value of 0,1 and 2 strings was entered as decision variable.

\subsubsection{Diesel generator modeling}

A diesel generator consumes fuel to produce electricity, and possibly heat as a by-product. The fuel curve is assumed as a straight line with a y-intercept and uses (6) for the generator's fuel consumption. Diesel generators are added to the microgrid system to cover the peak load. Moreover, they can supply the electric demand when the RES system is producing insufficient power.

$F=F_{0} Y_{\text {gen }}+F_{1} P_{\text {gen }}$

where $F_{0}$ the fuel curve intercept coefficient; $F_{1}$ the fuel curve slope; $Y_{\text {gen }}$ the rated capacity of the generator; and $P_{g e n}$ the electrical output of the generator.

Three diesel generator sets are installed in the existing system (one with a capacity of $380 \mathrm{~kW}$ and the second, third sets with a capacity of $1055 \mathrm{~kW}$ each). The capital cost is not considered as these are already installed but operation and maintenance cost of $0.002 \$$ /hour was taken into account. Cost of the diesel is $0.9 \$ /$ liter. The lifetime of diesel generator set is 15000 operating hour and the minimum load factor is $30 \%$. In the decision variable, ' 0 ' value was also included to obtain the most optimal unit.

\subsubsection{Converter modeling}

The rating of the converter (working as both rectifier and inverter) is chosen according to the total PV panel output, as the total PV panel output is converted in to AC by the converter. Hence, the size considered for converter is $125 \mathrm{~kW}$ to $275 \mathrm{~kW}$, with a cost of $110 \$ / \mathrm{kW}$. The replacement cost is $100 \$ / \mathrm{kW}$. The lifetime of converter is 20 years with an efficiency of $95 \%$ in both the directions.

\subsubsection{Utility grid}

In this model, the building is connected to the utility grid, and the building produces maximum demand of $600 \mathrm{~kW}$ on the utility grid. The tariff of the electricity charged by the utility is $0.065 \$ / \mathrm{kWh}$ of energy consumption and demand rate of $5 \$ / \mathrm{kW} /$ month [39]. The interconnection charge paid to the utility is $8000 \$$.

\subsubsection{System control and constraints}

The dispatch strategy selected for this system is "load following" type. The simulation time step is kept at one hour [40] and is performed with the following constraints.

1) The operating reserve is set at $7 \%$ of the total energy demand and $20 \%$ of each solar and wind power output.

2) The minimum renewable fraction (RF) is set at $35 \%$, i.e. at any moment the minimum energy from RES is $35 \%$ of the total energy consumed at that moment.

3) Maximum annual capacity shortage is set at $0 \%$.

\subsubsection{System economics}

The lifetime of the project is considered for 25 years at an annual interest rate of $6 \%$ throughout. Also, it is supposed that there is no capacity shortage penalty. The overall microgrid system model is shown in Fig. 12.

\section{Energy management strategy}

While simulating the proposed system, it was assumed that the grid is supplying rated energy, and RES produces nominal power throughout the project lifecycle, which is not obvious. Again, while perceiving the grid in Indian context, the grid outage and load shedding occur in an

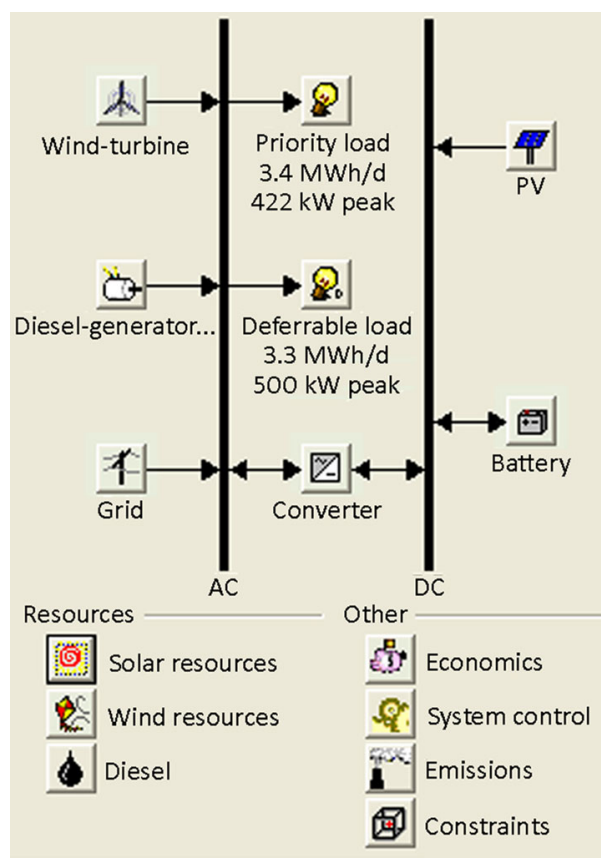

Fig. 12 Microgrid system model 
unpredictable manner. In this case, the microgrid designer faces a major challenge as to how reliability can manage and coordinate with the energy system. In simple term, managing the energy system means, how smartly use the available energy from all the sources to meet the load reliably [41, 42]. A simplified energy management method is presented here by considering four operation states.

\subsection{Normal operating condition}

In this state, it is assumed that the grid is supplying required energy and the RES are producing energy as per the nominal rating. In this case, just like the "load following" strategy, the priority loads are served by the grid and the deferrable loads are served by the RES. Excess renewable energy is used to charge the battery.

\subsection{Grid outage}

This state occurs during load shedding or an occurrence of fault in the transmission or distribution lines so that the utility is unable to serve the load. Simulation result shows that the renewable sources in the system produce $38 \%$ of total energy in a year with minimum renewable fraction of $35.6 \%$. Thus in this state, the energy produced from the renewable source is fed to the most important priority load (i.e. UPS load which is $32 \%$ of total energy consumption at any time). The excess renewable energy can be fed to other priority loads in the order of lighting, elevator, etc.

\subsection{Unavailability of renewable energy sources}

Sometimes due to constant poor solar radiation and wind speed less than the cut-in speed of the turbine, the renewable energy sources do not respond. During such period, the grid energy can be used to serve the entire priority load and a fraction of important deferrable load.

\subsection{Total blackout}

In this state, it is assumed that, the unavailability of the RES due to climatic condition and grid outage occurs at the same time. This can be the worst case and may rarely occur. In such scenario, the system is also capable to meet the priority load. Fig. 13 shows the frequency of state of charge (SOC) of the battery. It is clear that around $57 \%$ time in a year, the battery is in $100 \%$ SOC. Besides this, the building installed the diesel generator set which can be synchronized on demand. Battery and diesel generator set can serve the priority load and can also be extended up to certain deferrable load.

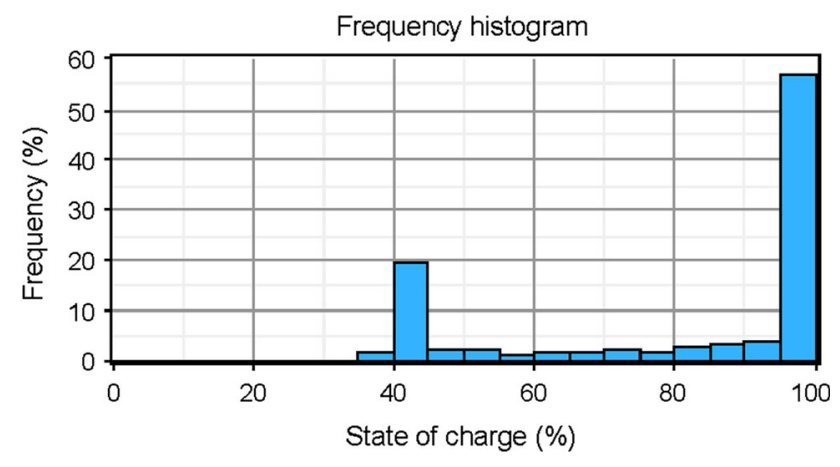

Fig. 13 Frequency of SOC of battery bank over year

\section{Simulation results}

The microgrid architecture is simulated in various aspects based on the variations in load profile, component cost and size, system constraints, control strategy, and system economics. The cumulative simulation results can be segregated as follows.

1) Energy management results

2) Optimization results

3) Sensitivity analysis results

\subsection{Energy management results}

Energy management results indicate the energy availability and transactions between microgrid and utility grid as shown in Figs. 14, 15, 16, 17, 18, 19 and 20 respectively.

\subsection{Optimization results}

HOMER considers all the possible combinations that are available in the search space to form the microgrid and

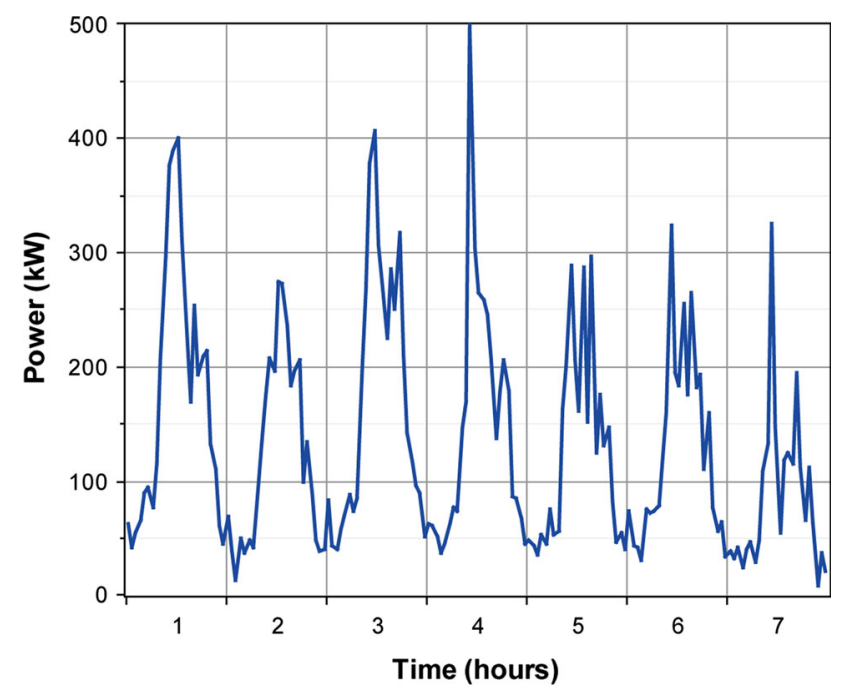

Fig. 14 Hourly load variation of the building 


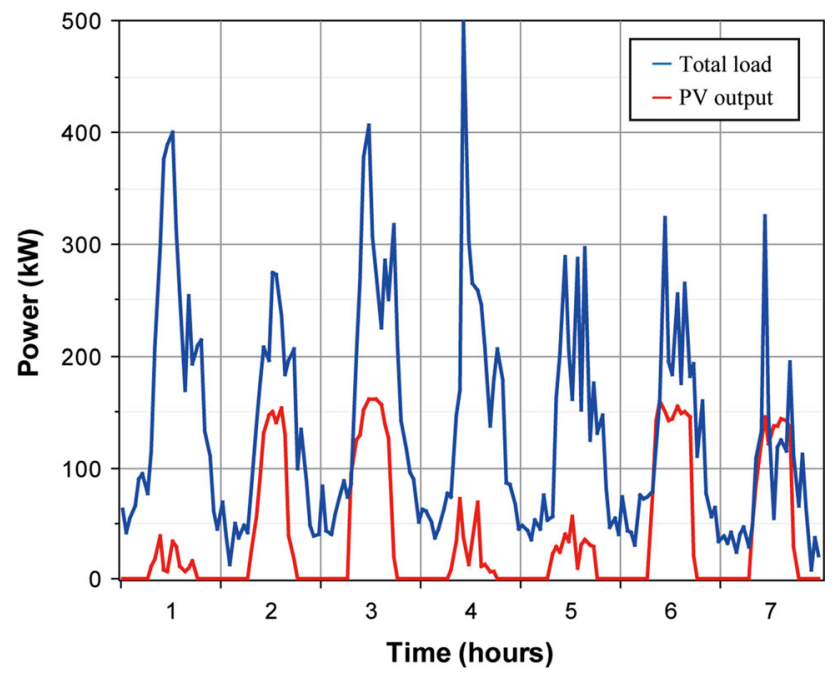

Fig. 15 Hourly load variation (Vs.) PV system output

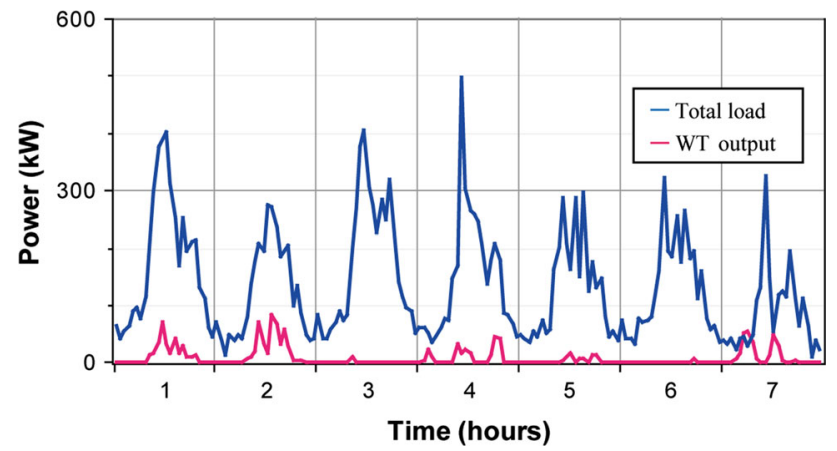

Fig. 16 Hourly load variation (Vs.) WT system output

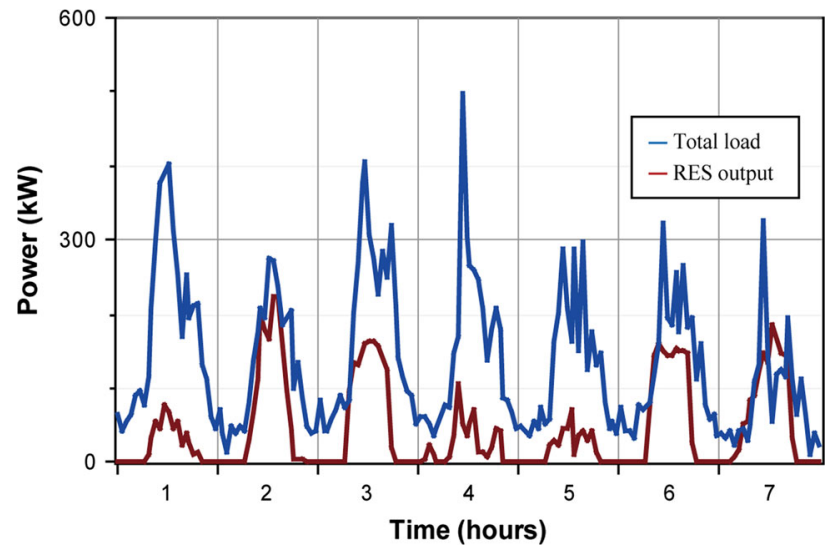

Fig. 17 Hourly load variation (Vs.) total RES system output

checks the feasibility of each system configuration by imposing all the user specified constraints. TNPC for all the feasible system is calculated and sorted accordingly. Table 2 ranks the list of categorized optimization results

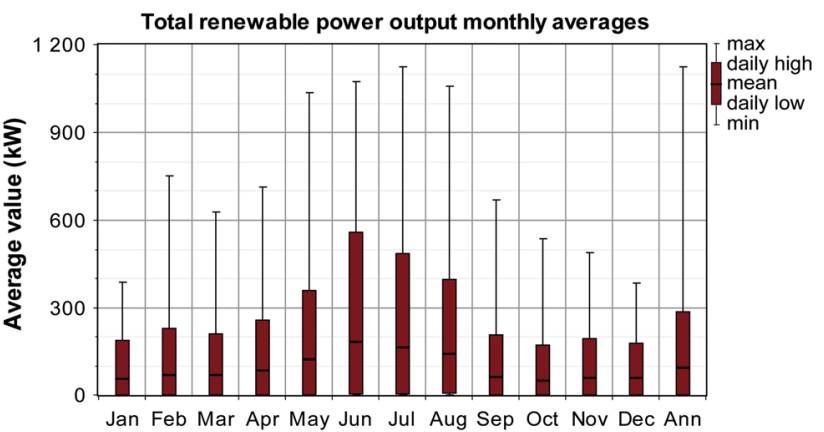

Fig. 18 Total RES power generation monthly wise in a year

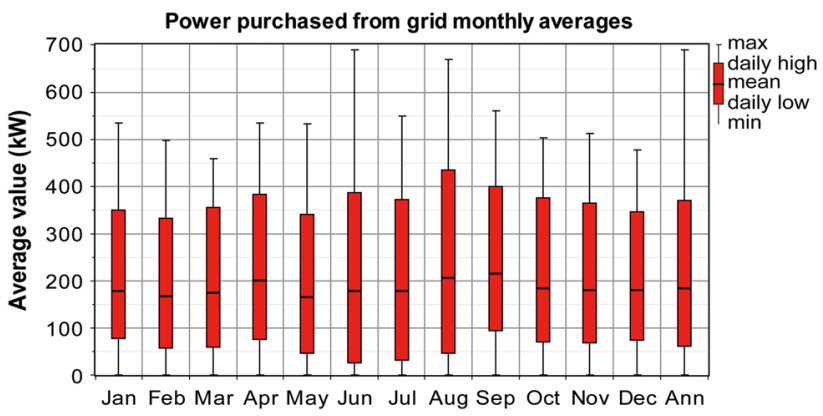

Fig. 19 Power purchased from grid monthly wise in a year

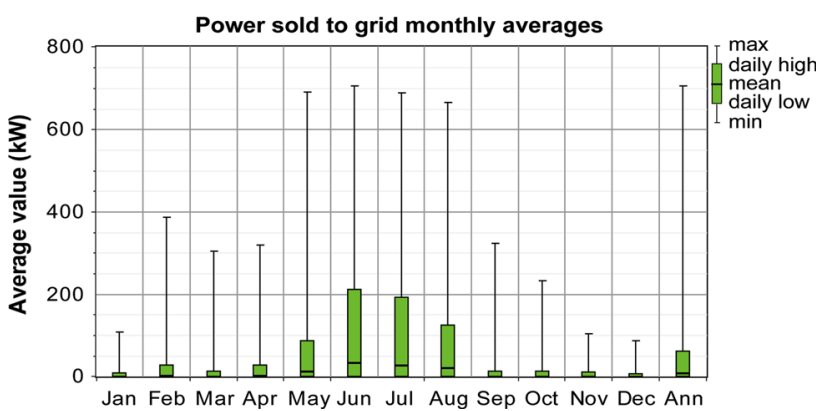

Fig. 20 Power sold to grid monthly wise in a year

for the microgrid. From the optimization result, it is clear that the most economic system configuration consists of the $180 \mathrm{~kW}$ PV array, three WTs, one battery string, a $160 \mathrm{~kW}$ converter and a grid connection having the demand of $600 \mathrm{~kW}$. The TNPC for this configuration is $2878236 \$$.

The breakdown of TNPC is as follows: 968589 \$ capital cost; 27248 \$ replacement cost; 1885545 \$ operation and maintenance cost; $0 \$$ fuel cost; and $3146 \$$ salvage value. This system has levelized $0.092 \$ / \mathrm{kWh}$ cost of energy and produced $35.6 \%$ minimum renewable energy. The considered 'zero' capital cost for diesel generator set does not impact on TNPC, as the optimal configuration does not include diesel generator set. Fig. 21 presents the electricity produced from different sources in a year. 
Table 2 Optimization result of proposed microgrid system

\begin{tabular}{|c|c|c|c|c|c|c|c|c|c|c|}
\hline $\begin{array}{l}\mathrm{PV} \\
(\mathrm{kW})\end{array}$ & WT & $\begin{array}{l}\mathrm{DG} \\
(\mathrm{kW})\end{array}$ & Battery & $\begin{array}{l}\text { Converter } \\
(\mathrm{kW})\end{array}$ & $\begin{array}{l}\text { Grid } \\
(\mathrm{kW})\end{array}$ & Initial capital & $\begin{array}{l}\text { Operating cost } \\
\text { (\$/year) }\end{array}$ & Total NPC & $\begin{array}{l}\mathrm{COE} \\
(\$ / \mathrm{kWh})\end{array}$ & $\begin{array}{l}\text { Ren. } \\
\text { fraction }\end{array}$ \\
\hline 180 & 3 & & 33 & 160 & 600 & 968589 & 149385 & 2878236 & 0.092 & 0.36 \\
\hline 170 & 3 & 380 & 33 & 170 & 600 & 947967 & 158841 & 2978492 & 0.096 & 0.35 \\
\hline 180 & 3 & 380 & & 170 & 600 & 956752 & 159508 & 2995795 & 0.096 & 0.36 \\
\hline
\end{tabular}

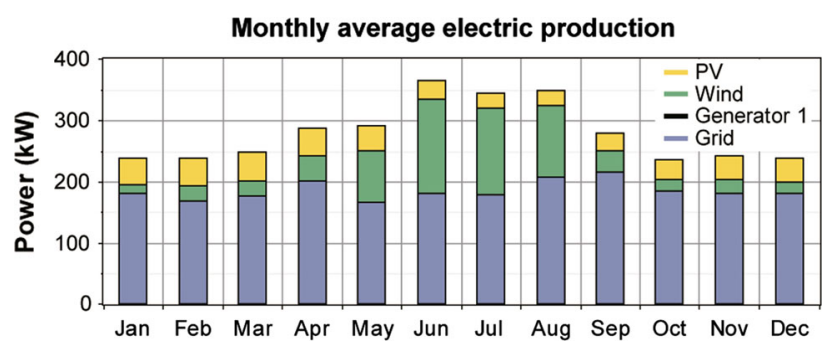

Fig. 21 Energy distribution from different sources in a year

The system has unmet load of only $1167 \mathrm{kWh} /$ year which is $0.05 \%$ of the total load. The total annualized cost is calculated [43]. In comparison, the grid-only connected system, that has a total annualized cost of 240000 \$ and microgrid system, that has total annualized cost of 225155 \$ produces savings of 14845 \$ per year. Table 3 shows a comparison between the existing grid-only connected system and the proposed microgrid system.

\subsection{Sensitivity analysis results}

As there are several sensitivity variables on which the user has no control, several sensitivity analyses were also performed on the optimal system configuration to guarantee that the proposed system configuration is optimal, robust and adaptable in unanticipated variances with respect to best estimated value. Some examples of such variable are environment changes like solar radiation and wind speed variation, variation in the total electricity consumed, grid tariff and demand rate variation, etc.

\subsubsection{Effect of solar radiation and wind speed variations}

The solar radiation and wind speed is allowed to vary from $90 \%$ to $110 \%$ of its measured value. For all the values in this range, simulation is done and the results

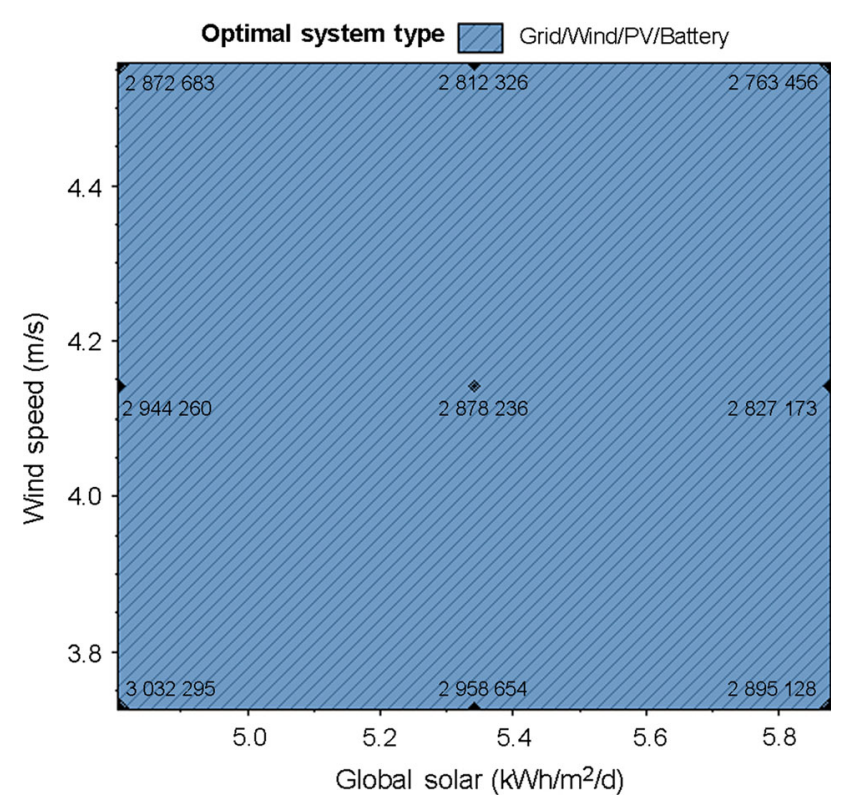

Fig. 22 Sensitivity for solar radiation and wind speed variation

indicate that the same system configuration is optimal for this variation. The sensitivity result and TNPC variations are shown in Figs. 22 and 23 respectively.

\subsubsection{Effect of electricity consumption variations}

As the connected load or total electric consumption in the building will not remain constant throughout the lifetime of the project, it is also considered as one of the sensitivity variable. Both priority and deferrable loads are varied from $100 \%$ to $105 \%$ of the present value. For this variation, the sensitivity result shows that the same system type is optimal. It is also observed that priority load variation is more influential to TNPC than deferred load. Fig. 24 illustrates the variation of TNPC with load.

Table 3 Comparison between existing system and microgrid

\begin{tabular}{llll}
\hline Load category & Grid-only connected system & Hybrid power based microgrid & Savings $(\%)$ \\
\hline Annualized cost & $240000 \$$ & $225155 \$$ & 6.18 \\
$\mathrm{CO}_{2}$ emission & $2090577 \mathrm{~kg} /$ year & $1288131 \mathrm{~kg} /$ year & 38.3 \\
\hline
\end{tabular}




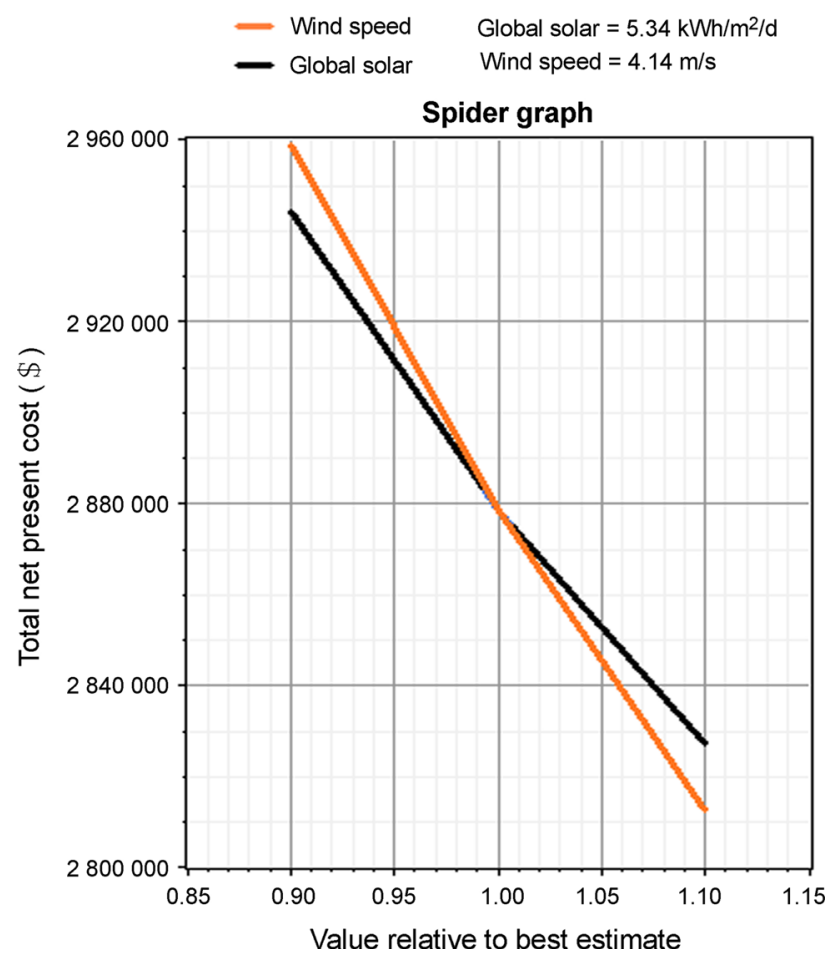

Fig. 23 Variation of TNPC with solar radiation and wind speed

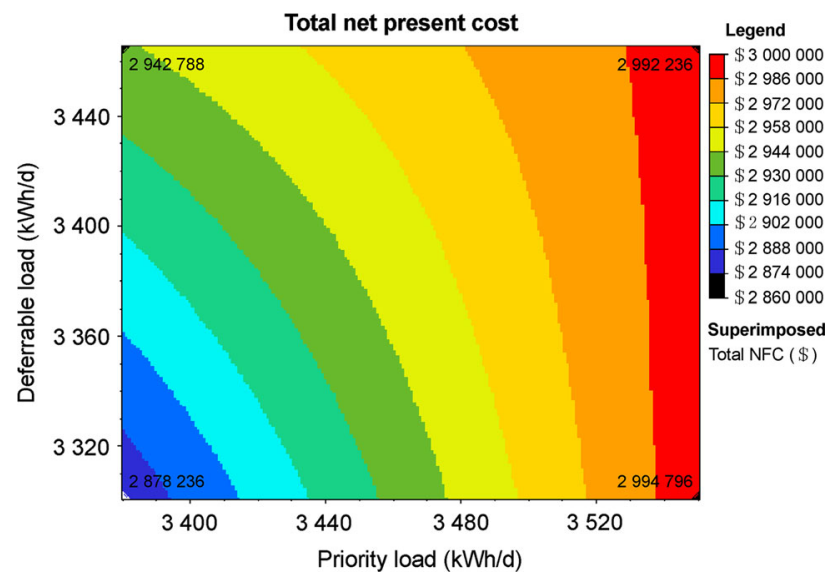

Fig. 24 Surface plot for variation of TNPC with load

\subsubsection{Effect of utility grid tariff variations}

As grid tariff keeps increasing to influence customer behavior, it is taken as another sensitivity variable for the evaluation. In this case, the grid tariff is allowed to vary up to $0.085 \$ / \mathrm{kWh}$ and demand rate is also varied from 5 to $6 \$ / \mathrm{kW} / \mathrm{month}$. The sensitivity result for grid tariff and demand rate variation shows that beyond grid tariff of $0.07 \$ / \mathrm{kWh}$, battery bank is discarded instead, the capacity

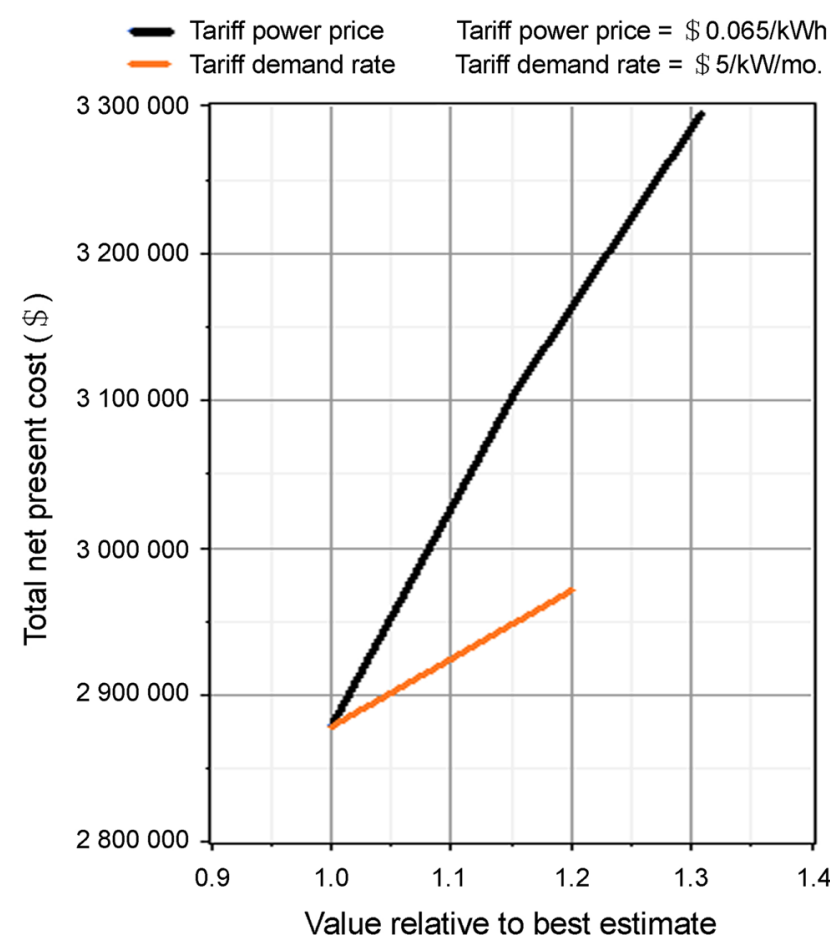

Fig. 25 Variation of TNPC with grid tariff rate and demand rate

of the PV is increased. Fig. 25 shows that the TNPC is more sensitive to grid power price to that of demand rate.

\subsubsection{Effect of variation of minimum renewable fraction and shortage capacity fraction}

It is considered that the proposed system must able to produce $35 \%$ minimum renewable energy of the total electric energy consumed, which is a user specified constraints and depends on system design. This value can be varied as per the user choice and causes remarkable impact on the TNPC. Similarly, one more constraint imposed during the simulation process is maximum annual capacity shortage. This parameter is set at ' 0 ' as the building cannot compromise with reliability or interruption in energy supply. With this assumption, the system configuration is estimated that the system is able to supply peak load, which even occurs for a short interval.

However, practically if the peak load for a very short period can be avoided, then the system configuration and NPC may be other than as above. Thus, a sensitivity analysis for variation of minimum renewable fraction from $35 \%$ to $40 \%$, and maximum annual capacity shortage vary from $0 \%$ to $1 \%$ is performed. It is observed from the simulation result that, for this variation, beyond minimum capacity shortage fraction of $0.37 \%$, battery is discarded from the system. TNPC variation is shown in Fig. 26. 


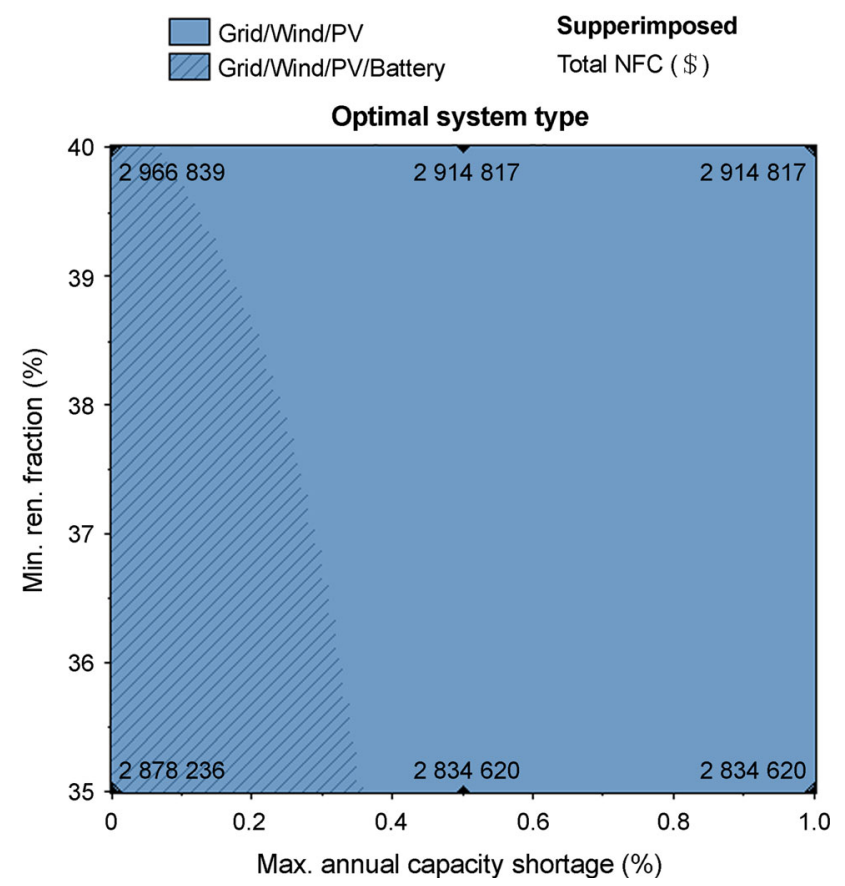

Fig. 26 Sensitivity for minimum renewable fraction variations

\section{Conclusion}

Hence, the design aspects of renewable energy based microgrid are discussed in this paper. The study is conducted for an urban building having $3.4 \mathrm{MWh} /$ day priority load along with a $3.3 \mathrm{MWh} /$ day deferrable load. The cumulative merits of this system are as follows.

1) The most economic system configuration is achieved for the combination of $600 \mathrm{~kW}$ utility grid contribution, $180 \mathrm{~kW}$ PV contribution, and 3 units WT contribution $(50 \mathrm{~kW}$ for each, $150 \mathrm{~kW}$ in total), 33 batteries (1 string) and a $160 \mathrm{~kW}$ converter.

2) The levelized cost of energy of such system is achieved as $0.092 \$ / \mathrm{kWh}$ which is less than the gridonly connected system.

3) Besides, the system is environment friendly and beneficial for sustainable development which leads to $6.18 \%$ annual cost savings and reduces $\mathrm{CO}_{2}$ emissions by $38.3 \%$.

4) From sensitivity results, it was observed that the system work satisfactorily in a range of varying scenarios such as solar radiation, wind speed and increase in energy consumption.

5) The energy management strategy developed ensures uninterruptable and reliable supply for the priority load for smooth running of the business.
Open Access This article is distributed under the terms of the Creative Commons Attribution License which permits any use, distribution, and reproduction in any medium, provided the original author(s) and the source are credited.

\section{References}

[1] National Action Plan on Climate Change, Ministry of Environment, Forest, and Climate Change, Government of India. http://envfor.nic.in/ccd-napcc

[2] Thomas S (2014) Are low-carbon generation and competitive electricity markets compatible? Evidence from the UK electricity market reforms. In: Brunnengräber A, Di Nucci MR (eds) Im Hürdenlauf zur Energiewende. Springer, Berlin, pp 153-164

[3] Nelson D (2014) Roadmap to a low carbon electricity system in the US and Europe. Climate Policy Initiative, San Francisco

[4] Smart grid vision and roadmap for India. India Ministry of Power (2013)

[5] Scheer D, Konrad W, Scheel O (2013) Public evaluation of electricity technologies and future low-carbon portfolios in Germany and the USA. Energ Sustain Soc 3:1-13

[6] Kuo TC, Chen HM, Liu J et al (2014) Applying multi-objective planning in low-carbon product design. Int J Precis Eng Manuf 15(2):241-249

[7] Zhang Q, Tezuka T, Mclellan BC et al (2012) Scenario analysis of low-carbon smart electricity systems in Japan in 2030. In: Yao T (ed) Zero-carbon energy Kyoto 2011, Part 1. Springer, Berlin, pp 33-44

[8] Pudjianto D, Aunedi M, Djapic P et al (2014) Whole-systems assessment of the value of energy storage in low-carbon electricity systems. IEEE Trans Smart Grid 5(2):1098-1109

[9] Zeng B, Zhang JH, Yang X et al (2014) Integrated planning for transition to low-carbon distribution system with renewable energy generation and demand response. IEEE Trans Power Syst 29(3):1153-1165

[10] Chen Q, Kang CQ, Xia Q et al (2010) Power generation expansion planning model towards low-carbon economy and its application in China. IEEE Trans Power Syst 25(2):1117-1125

[11] Ji Z, Kang CQ, Chen QX et al (2013) Low-carbon power system dispatch incorporating carbon capture power plants. IEEE Trans Power Syst 28(4):4615-4623

[12] Lu SY, Lou SH, Wu YW et al (2013) Power system economic dispatch under low-carbon economy with carbon capture plants considered. IET Gener Transm Distrib 7(9):991-1001

[13] Turconi R, Tonini D, Nielsen CFB et al (2014) Environmental impacts of future low-carbon electricity systems: detailed life cycle assessment of a Danish case study. Appl Energy 132: 66-73

[14] Roelicha K, Dawson DA, Purnell P et al (2014) Assessing the dynamic material criticality of infrastructure transitions: a case of low carbon electricity. Appl Energy 123:378-386

[15] Walmsley MRW, Walmsley TG, Atkins MJ et al (2014) Minimising carbon emissions and energy expended for electricity generation in New Zealand through to 2050. Appl Energy 135:656-665

[16] Zhang Q, Mclellan BC, Utama NA et al (2011) A methodology for designing future zero-carbon electricity systems with smart grid and its application to Kansai area, Japan. In: Design for innovative value towards a sustainable society: Proceedings of the 7th international symposium on environmentally conscious design and inverse manufacturing (EcoDesign'11), Kyoto, Japan, 30 Nov-2 Dec 2011, pp 50-54 
[17] Jin C, Wang P, Xiao JF et al (2014) Implementation of hierarchical control in DC microgrids. IEEE Trans Ind Electron 61(8):4032-4042

[18] Cristea C, Lopes JP, Eremia M et al (2007) The control of isolated power systems with wind generation. In: Proceedings of the 2007 IEEE Lausanne power technology conference, Lausanne, 1-5 Jul 2007, pp 567-572

[19] Mohd A, Ortjohann E, Sinsukthavorn W et al (2009) Supervisory control and energy management of an inverter-based modular smart grid. In: Proceedings of the IEEE PES power systems conference and exposition (PSCE'09), Seattle, 15-18 Mar 2009, 6 pp

[20] Omari O, Ortjohann E, Mohd A et al (2007) An online control strategy for DC coupled hybrid power systems. In: Proceedings of the 2007 IEEE power engineering society general meeting, Tampa, 24-28 Jun 2007, 8 pp

[21] Johnson NG, Glassmire JW, Lilienthal PD (2012) Comparing power system architectures for domestic lighting in isolated rural villages with HOMER. In: Proceedings of the 2012 IEEE global humanitarian technology conference (GHTC'12), Seattle, 21-24 Oct 2012, pp 375-380

[22] Anwari M, Rashid MIM, Muhyiddin HTM et al (2012) An evaluation of hybrid wind/diesel energy potential in Pemanggil Island Malaysia. In: Proceedings of the 2012 international conference on power engineering and renewable energy (ICPERE'12), Bali, 3-5 Jul 2012, 5 pp

[23] Yadav DK, Girimaji SP, Bhatti TS (2012) Optimal hybrid power system design using HOMER. In: Proceedings of the IEEE 5th India international conference on power electronics (IICPE'12), Delhi, 6-8 Dec 2012, 6 pp

[24] Kansara BU, Parekh BR (2011) Modeling and simulation of distributed generation system using HOMER. In: Proceedings of the 2011 IEEE international conference on recent advancements in electrical, electronics and control engineering (ICONRAEeCE'11), Sivakasi, 15-17 Dec 2011, pp 328-332

[25] Sureshkumar U, Manoharan PS, Ramalakshmi APS (2012) Economic cost analysis of hybrid renewable energy system using HOMER. In: Proceedings of the 2012 international conference on advances in engineering, science and management (ICAESM'12), Nagapattinam, 30-31 Mar 2012, pp 94-99

[26] De Brabandere K, Vanthournout K, Driesen J, et al (2007) Control of microgrids. In: Proceedings of the 2007 IEEE power engineering society general meeting, Tampa, 24-28 Jun 2007, 7 pp

[27] Alam MS, Gao DW (2007) Modeling and analysis of a wind/PV/ fuel cell hybrid power system in HOMER. In: Proceedings of the 2nd IEEE conference on industrial electronics and applications (ICIEA'07), Harbin, 23-25 May 2007, pp 1594-1599

[28] Rohani A, Mazlumi K, Kord H (2010) Modeling of a hybrid power system for economic analysis and environmental impact in HOMER. In: Proceedings of the 18th Iranian conference on electrical engineering (ICEE'10), Isfahan, 11-13 May 2010, pp 819-823

[29] Konig O, Hametner C, Prochart G et al (2014) Battery emulation for power-HIL using local model networks and robust impedance control. IEEE Trans Ind Electron 61(2):943-955

[30] Reddy YJ, Kumar YVP, Raju KP et al (2012) Retrofitted hybrid power system design with renewable energy sources for buildings. IEEE Trans Smart Grid 3(4):2174-2187

[31] Nehrir MH, Wang C, Strunz K et al (2011) A review of hybrid renewable/alternative energy systems for electric power generation: configurations, control, and applications. IEEE Trans Sustain Energ 2(4):392-403

[32] Shaahid SM, El-Amin I (2009) Techno-economic evaluation of off-grid hybrid photovoltaic-diesel-battery power systems for rural electrification in Saudi Arabia- a way forward for sustainable development. Renew Sustain Energy Rev 13(3):625-633
[33] Dihrab SS, Sopian K (2010) Electricity generation of hybrid PV/ wind systems in Iraq. Renew Energy 35(6):1303-1307

[34] Microgrid Power System Design Services Using HOMER. http://www.homerenergy.com/microgrid_power_system_design_ services.html

[35] Felix A, Simoes MG (2006) Integration of alternative sources of energy. IEEE Press, Hoboken

[36] Hyderabad planet. www.hyderabadplanet.com

[37] Atmospheric science data center (2013) http://eosweb.larc.nasa. gov

[38] The mean monthly wind speed in Hyderabad, India. http:// www.weather-and-climate.com/average-monthly-Wind-speed, Hyderabad,India

[39] Southern Power, Distribution Company of T.S.Limited (2014) http://www.apcentralpower.com

[40] Barley CD, Winn CB (1996) Optimal dispatch strategy in remote hybrid power systems. Sol Energy 58(4-6):165-179

[41] Jalivand A, Kord H, Rohini A (2009) Design, control \& power management for a hybrid PV/WG/FC system for standalone applications. In: Proceedings of the 14th electrical power distribution conference (EPDC'09), Kerman

[42] Wang CS, Nehrir MH (2008) Power management of a standalone wind/photovoltaic/fuel-cell energy system. IEEE Trans Energy Convers 23(3):957-967

[43] Nelson DB, Nehrir MH, Wang C (2006) Unit sizing and cost analysis of stand-alone hybrid wind/PV/fuel cell power generation system. Renew Energy 31(10):1641-1656

Y. V. PAVAN KUMAR (S'14) received B.Tech in Electrical and Electronics Engineering in 2007 from JNTUH, India; M.Tech in Instrumentation and Control Systems in 2011 from JNTUK, India; and currently pursuing Ph.D in Electrical Engineering in the area of Smart Microgrids at Indian Institute of Technology Hyderabad (IITH), India. Prior to this, he has worked as a design engineer for Control Systems, Power Systems, and Engineering Test Systems in the departments of Aerospace engineering and Energy Research \& Development center of Honeywell Technology Solutions Lab, India for 3 years. He also has 2.5 years of teaching experience in Electrical and Electronics Engineering for undergraduate and postgraduate students. He has published 42 papers in International Journals and Conferences, 2 Books, 3 Honeywell innovation disclosures. He has guided 6 M.Tech theses and 3 B.Tech theses. His research area includes Microgrids, Smartgrids, Advanced Control systems, and Artificial Intelligence. $\mathrm{He}$ is a student member of IEEE Power \& Energy Society, IEEE Communications Society, and IEEE Smart Grid Community.

Ravikumar BHIMASINGU obtained his Ph.D and M.Sc (Engg.) both in the Department of Electrical Engineering, Indian Institute of Science (IISc), Bangalore, India in the year 2009 and 2004 respectively. He obtained his B.Tech degree from Nagarjuna University, India in the year 2002. After completion of his Ph.D, he worked as a Senior Research Associate and Junior Research Associate both at the Department of Electrical Engineering, IISc. Later he joined Global R\&D Center, Crompton Greaves Ltd., Mumbai, India as a Senior Executive-Technology and served for 3 years from 2010 to 2013. Currently, he is working as an Assistant Professor in the department of Electrical Engineering at Indian Institute of Technology Hyderabad (IITH), India. His research interests include AI techniques applications to power systems security improvement, computer-aided power system analysis and modeling, and distribution system automation. He has authored 7 National and International Journal publications and 35 National and International Conference publications. 